\title{
Analysis of the Major Fe Bearing Mineral Phases in Recent Lake Sediments by EXAFS Spectroscopy
}

\author{
LORENZO SPADINI $^{1}$, MARKUS BOTT $^{2}$, BERNHARD WEHRLI $^{2, \star}$ and \\ ALAIN MANCEAU ${ }^{1,3}$ \\ ${ }^{1}$ Environmental Geochemistry Group, LGIT-IRIGM, University of Grenoble and CNRS, BP 53, \\ 38041 Grenoble France Cedex 9; ${ }^{2}$ Swiss Federal Institute for Environmental Science and \\ Technology (EAWAG) and Swiss Federal Institute of Technology (ETH), Limnological Research \\ Center CH-6047 Kastanienbaum, Switzerland; ${ }^{3}$ Present address: Hilgard Hall \#3110, University \\ of California, Berkeley, CA 94720-3110 USA
}

(Received: 26 August 2002; accepted: 1 August 2003)

\begin{abstract}
Extended X-ray absorption fine structure (EXAFS) spectroscopy and chemical analyses were combined to determine the Fe bearing minerals in recent lake sediments from Baldeggersee (Switzerland). The upper section of a laminated sediment core, deposited under eutrophic conditions, was compared to the lower part from an oligotrophic period. Qualitative analysis of FeK EXAFS agreed well with chemical data: In the oligotrophic section $\mathrm{Fe}(\mathrm{II})-\mathrm{O}$ and $\mathrm{Fe}(\mathrm{III})-\mathrm{O}$ species were present, whereas a significant fraction of $\mathrm{Fe}(\mathrm{II})-\mathrm{S}$ sulfides was strongly indicated in the eutrophic part. A statistical analysis was performed by least square fitting of normalized reference spectra. The set of reference minerals included Fe(III) oxides and Fe(II) sulfides, carbonates and phosphates. In the oligotrophic regime no satisfying fit was obtained using the set of reference spectra, indicating that siderite $\left(\mathrm{FeCO}_{3}\right)$ was not present in a significant amount in these carbonate-rich sediments. Simulated EXAFS spectra for a $\left(\mathrm{Ca}_{\mathrm{x}}, \mathrm{Fe}_{1-\mathrm{x}}\right) \mathrm{CO}_{3}$ solid solution allowed reconstructing the specific features of the experimental spectra, suggesting that this phase was the dominant Fe carrier in the oligotrophic section of the core. In the eutrophic part, mackinawite was positively identified and represented the dominant $\mathrm{Fe}$ (II) sulfide phase. This finding agreed with chemical extraction, which indicated that $18-40 \mathrm{~mol} \%$ of Fe was contained in the acid volatile iron sulfide fraction. EXAFS spectra of the eutrophic section were best fitted by considering the admixture of mackinawite and the $\mathrm{Fe}-\mathrm{Ca}$ carbonate phase inferred to be predominant in the oligotrophic regime.
\end{abstract}

Key words: acid volatile sulfides, EXAFS, iron carbonates, iron sulfides, lake sediments, mackinawite, selective extraction, solid solution, speciation

\section{Introduction}

In complex environmental systems like soils, aquifer material and sediments iron is typically present as a mixture of different mineral phases. Dissolution and precipitation of iron minerals are controlled by redox conditions and different microbial and geochemical processes (Davison, 1993; Burdridge, 1993; Cornell and Schwertmann, 1996; Hansel et al., 2001; Mettler et al., 2001). There is a considerable

\footnotetext{
$\star$ Author for correspondence.
} 
interest to analyze the dominant mineral form of iron present in these environments. Important parameters such as the adsorption capacity or the bioavailability for iron reducing organisms depend on the mineral phase (Taillefert et al., 2000). On the other hand, information on the oxidation state of Fe and the dominant phase provides important clues to the past and present redox conditions prevailing in a particular system (Bott, 2002; Schaller et al., 1997).

So far mainly chemical extraction methods were used as operational tools to distinguish different fractions of iron in soils and sediments. For a quantitative analysis of iron sulfides the extraction methods of acid volatile sulfide (ASV) and chromium reducible sulfide (CRS) reliably determine $\mathrm{FeS}$ and $\mathrm{FeS}_{2}$, respectively (Morse et al., 1987). In addition to these specific extractions the sequential extraction schemes were often used to discriminate between iron oxide, carbonate and phosphate phases. However, Nirel and Morel (1990) summarized the pitfalls of such methods. Recent studies proposed to combine chemical extractions with more direct methods such as diffraction, spectroscopy or microprobe analysis (Manceau et al., 2000). Among the spectroscopic methods Mossbauer (Drodt et al., 1997), XANES (Kuno et al., 1999) and EXAFS spectroscopy (Friedl et al., 1997) showed significant potential to identify poorly crystallized $\mathrm{Fe}$ minerals in sediments.

In this study we addressed the question whether the potential of EXAFS to discriminate between the dominant iron phases in recent lake sediments can actually be realized. We characterized sediment samples deposited under different redox conditions in a $65 \mathrm{~m}$ deep hard water lake by selective extraction methods. EXAFS spectra of sediment samples were recorded under strictly anaerobic conditions. In order to analyze the EXAFS data in detail, we compiled a database containing the EXAFS spectra of Fe reference minerals. This analysis was focused on the main sedimentary Fe minerals (excluding silicates), namely the oxides, sulfides, phosphates and carbonates. On the basis of this data set we performed an extensive regression analysis with the EXAFS spectra to evaluate the dominant Fe bearing phases in these recent lake sediments. The comparison of these EXAFS analysis with the results from selective chemical extractions allowed evaluating the detailed speciation of particulate iron in the lake sediment.

\section{Material, Methods and Sample Characterization}

\subsection{SAMPLING SITE AND CORE DESCRIPTION}

Sediment cores were taken at the deepest site $(65 \mathrm{~m})$ of Baldeggersee, a eutrophic hard water lake close to Lucerne, Switzerland. The sediments at this site are continuously varved since 1885. Lotter et al. (1997) and Schaller et al. (1997) analyzed the sediment characteristics of this varved section in detail. The $1.3 \mathrm{~m}$ long and $6 \mathrm{~cm}$ wide sediment cores were retrieved with an UWITEC gravity corer and sampled for geochemical analysis as described in detail in Bott, 2002. A second core was taken in September 1997 for the EXAFS analysis. A simplified sedimentological core profile is shown in Figure 1 and detailed in Table I. The samples 
\#1 to \#3 were collected in the $39 \mathrm{~cm}$ long black section from the recent eutrophic period. The remaining samples \#4 to \#10 came from the light gray section deposited earlier, when the lake was oligotrophic. Five of these samples (\#5, \#6, \#7, \#9 and \#10) corresponded to varve bundles deposited under anoxic conditions and 2 others (\#4 and \#8) were from homogeneous (bioturbated) sediments from oxic periods in the deep water.

\subsection{CHEMICAL ANALYSES}

The eutrophic section corresponded to the first $39 \mathrm{~cm}$ of the core and to the time span between 1885 and 1997. In this section selective extraction methods were applied in order to determine the Fe and $\mathrm{S}$ speciation. The $\mathrm{Fe}$ (III) and $\mathrm{Fe}$ (II) fractions relative to total Fe, the acid-volatile Fe(II)-sulfides (AVS), the chromiumreducible Fe(II)-sulfides (CRS), and the remaining non-sulfide $\mathrm{Fe}(\mathrm{II})$ fraction were analyzed. The AVS fraction is commonly assigned to mackinawite, troilite and pyrrhotite, and CRS compounds are attributed to the $\mathrm{FeS}_{2}$ minerals pyrite and marcasite (Morse et al., 1987). Details are described in Bott (2002). The resulting $\mathrm{Fe}$ speciation profile is given in Figure 1. The Fe(III) content varies from 7.7 mol\% Fetot near the sediment-water interface to more than $30 \%$ in the oligotrophic section of the core (Table I and Figure 1). CRS represents only a minor component with concentrations below 5.9\% in the EXAFS samples (Table I). The important fractions are AVS sulfides and the remaining non-sulfide Fe(II) fraction. AVS contributes between 7.3 and $85 \%$ to the total Fe fraction (Figure 1) with values for the EXAFS samples ranging from 18 to $40 \%$ (Table 1). For the non sulfide Fe(II) fraction minimum and maximum values in the core are 15 and $86 \%$ of total $\mathrm{Fe}$, respectively. Total $\mathrm{P}$ concentrations are low as compared to total Fe concentrations (less than $11 \%$ of total iron, Table I). In the oligotrophic section the AVS fraction is diminished and the non sulfide Fe(II) fraction dominates the speciation. The Fe(III) fraction increases with depth and becomes the second fraction of importance. Thus eutrophic samples have generally low CRS, Fe(III) and phosphate concentrations. As a consequence, iron oxides, pyrite and iron phosphates will be difficult to detect in these samples from the eutrophic lake by EXAFS spectroscopy. By contrast, the $\mathrm{Fe}$ (II) sulfides and the undetermined $\mathrm{Fe}$ (II) fraction are significant with respect to EXAFS sensitivity. In the oligotrophic section the non sulfide Fe(II) fraction dominates the Fe speciation.

\subsection{X-RAY DIFFRACTION ANALYSIS}

Powder diffraction spectra were recorded on a SIEMENS D5000 spectrometer with a rotating sample disk and a solid state detector. The sample powder was dried under inert atmospheric conditions. Dominant signals were those of quartz and calcite. The minor signals could be attributed to feldspath (albite), mica (muscovite), 


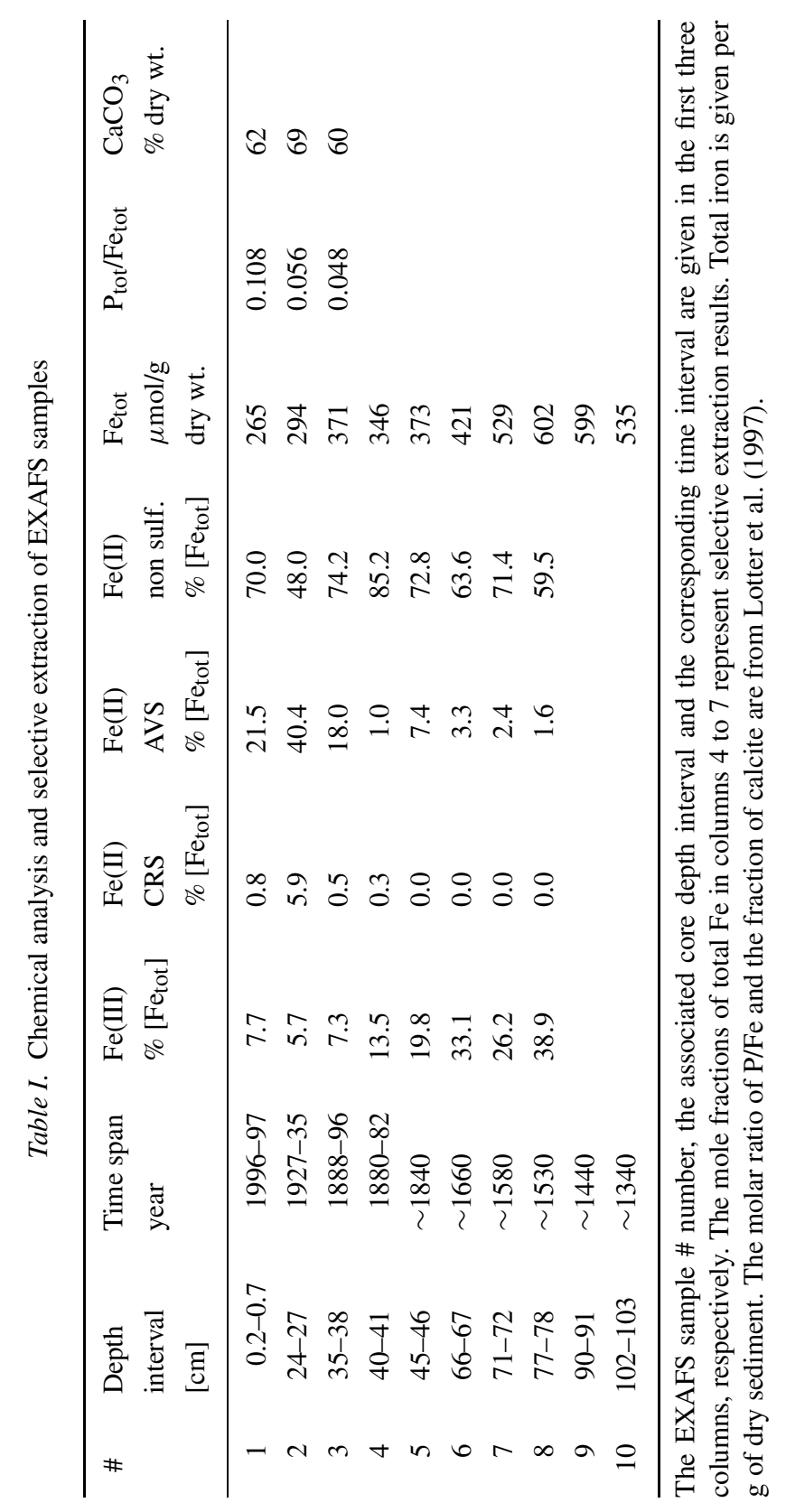




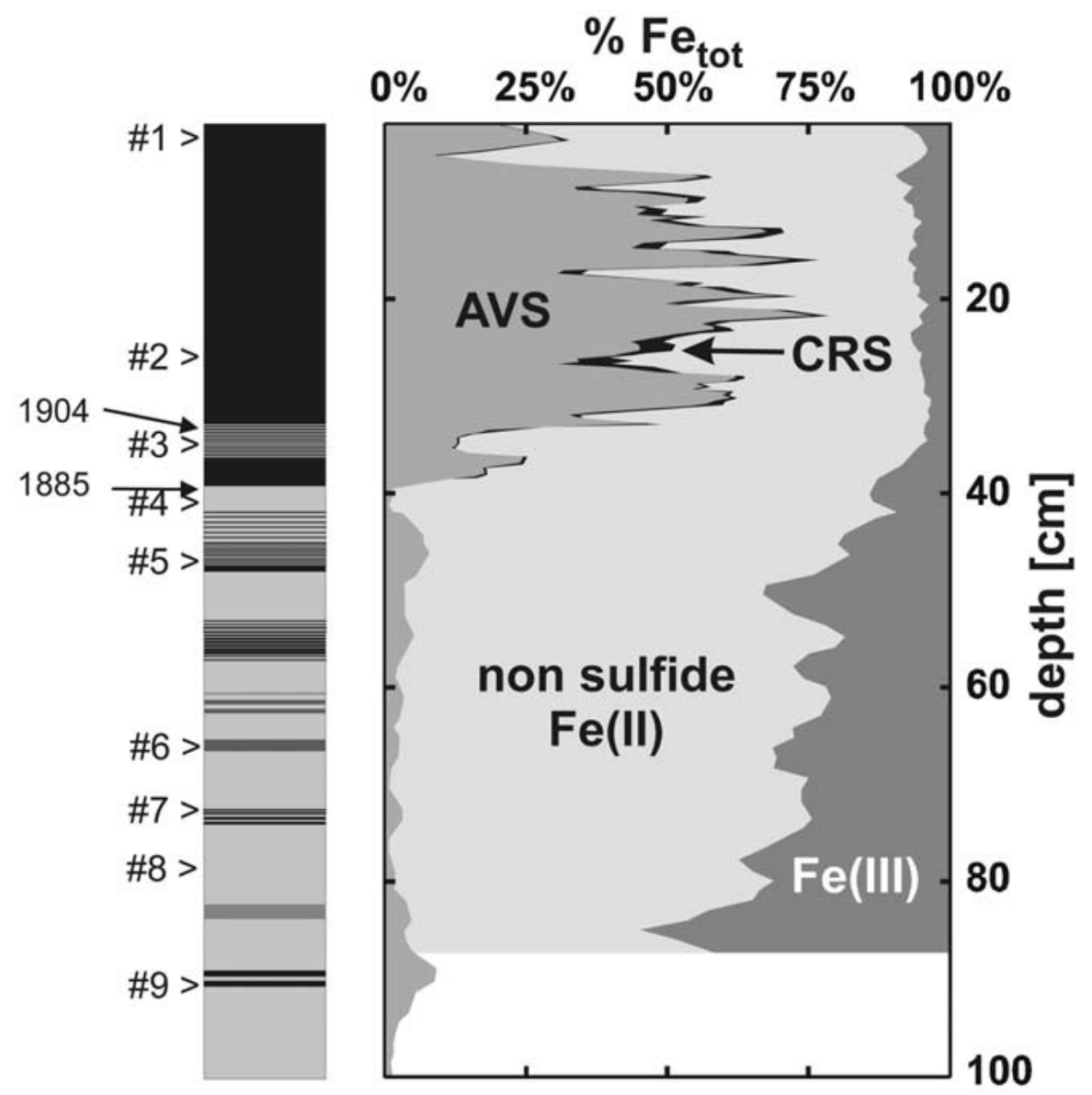

Figure 1. Schematic stratigraphy of sediment core from the deepest site in Baldeggersee (left). The eutrophic section is represented in black and the oliogotrophic section in light gray. Black line bundles indicate varves in the oligotrophic section. The symbol '>' indicates the sampling locations for the EXAFS analysis. The relative Fe contribution of the AVS, CRS, Fe(II), Fe(III) fractions from selective extraction are given in mole\% with respect to total Fe.

chlorite (chlinochlore) and dolomite. Other minerals, noticeably Fe compounds, were not found in the diffraction spectra.

\subsection{SAMPLE PREPARATION, EXAFS DATA COLLECTION AND REDUCTION}

Immediately after retrieving the cores on the lake the sediment tubes were closed by airtight rubber stoppers and transported to the synchrotron facility. EXAFS analysis took place no later than $60 \mathrm{~h}$ after coring. This storage procedure was checked for oxidation and no transformation of iron sulfides into iron oxides could be detected on the time scale of 1-2 weeks. The sample preparation was performed under an inert atmosphere in a glove box at the synchrotron laboratory. Adequate 
core sampling in vertical position was achieved by means of an airtight core gate and a core crank. FeK edge EXAFS measurements were performed at the EXAFS D42 station of the L.U.R.E synchrotron radiation facility in Orsay, Paris. Spectra were recorded in fluorescence or transmission mode depending on the metal concentration. X-ray absorption spectra were treated following a standard procedure (Koningsberger and Prins, 1988). The terminology used here corresponds to that given in Sarret et al. (1998).

\subsection{ANALYSIS OF BOND DISTANCES IN IRON MINERALS}

Our analysis of FeK edge EXAFS data from these heterogeneous sediment samples is based on the hypothesis that Fe-carbonates, -phosphates, -sulfides and -oxides may be discriminated according to their Fe-1st shell distances. This working hypothesis needs to be verified. The inter-atomic distances of natural reference minerals are thus compared in Figure 2: gray-shaded areas mark the distribution of the Fe1 st shell distances of the given mineral groups. Effectively, the gray box for the Fe-sulfide 1st shell distances reflects the largest distances. Almost all individual Fe-sulfide 1st shell distances are longer than those of other groups. Octahedrally coordinated $\mathrm{Fe}(\mathrm{II})-\mathrm{S}(-\mathrm{II})$ minerals (smythite, pyrrhotite, troilite) form a distinguished group of maximum $\mathrm{Fe}-\mathrm{S}$ bond length as compared to $\mathrm{Fe}(\mathrm{II})-\mathrm{S}(-\mathrm{I})$ minerals - as is expected from crystal chemical rules. Shortest Fe-S distances are found for tetrahedrally coordinated $\mathrm{S}$ atoms (mackinawite, greigite). Compared to $\mathrm{Fe}-$ sulfides, $\mathrm{Fe}(\mathrm{II})-\mathrm{O}$ carbonate and phosphate distances are shorter. The $\mathrm{Fe}(\mathrm{III})-\mathrm{O}$ group exhibits the shortest bond lengths. Average first shell distances can be determined with a precision of $\geq 0.1 \AA$ from EXAFS spectra at the FeK edge. Figure 2 therefore shows that a coarse speciation of the main Fe mineral groups is possible for mineral phases, which have a significant contribution to sediment material.

\section{Results and Discussion}

\subsection{QUALITATIVE SPECTRA ANALYSIS}

The normalized EXAFS FeK edge $\mathrm{k}^{2} \chi(\mathrm{k})$ spectra of the sediment samples are shown in Figure 3. The spectra represent the FeK edge X-ray absorption fine structure of the sediment samples, recorded with increasing wave number, i.e., with increasing energy relative to the $\mathrm{Fe}_{\mathrm{K}}$ edge. The top three samples \#1 to \#3 relate to the eutrophic lake regime whereas the seven lower samples \#4 to \#10 come from sediment strata deposited under oligotrophic conditions. Generally all 10 spectra are close in shape. At $\mathrm{k}<7 \AA^{-1}$, thereon referred as low $\mathrm{k}$ range, the signal originates from a single oscillation which relates essentially to the first coordination shell of the central Fe atom. At $8 \AA^{-1}$ a beating pattern is observed which is common to all spectra. The generalized occurrence of this signal could indicate the occurrence of a unique mineral phase in all of these samples, i.e., in both the eutrophic and oligotrophic range. This feature will be discussed in more 


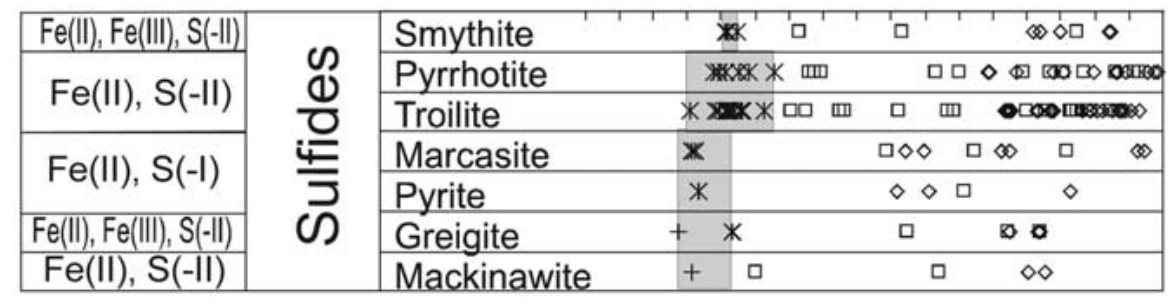

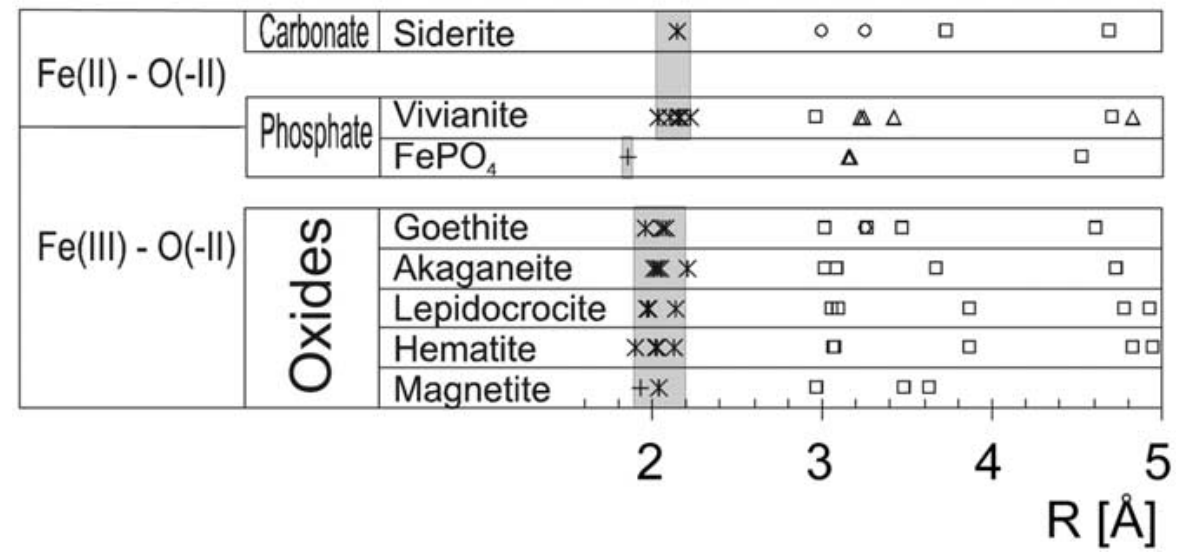

Figure 2. Fe-atomic shell distances of minerals considered in the present study. Oxidation states and the mineral groups are given in the left column. The first shell $\mathrm{Fe}-\mathrm{O}$ and $\mathrm{Fe}-\mathrm{S}$ distances for each mineral are given in gray. Symbols $*$ and + stand for octahedral and tetrahedral coordination. For the next-nearest shells $\square, \Delta, \diamond$ and $\bigcirc$ refer to Fe, P, S and O neighbors, respectively. Oxygen shells are plotted up to a distance of $d(\mathrm{Fe}-\mathrm{O})=3.4 \AA$.

detail later. In the low $\mathrm{k}$ range the top 3 spectra differ nevertheless significantly from the other ones. The raw spectra of the oligotrophic group (\#4 to \#10) look almost identical, they have all a $\mathrm{k}^{2} \chi(\mathrm{k})$ maximum at $4.0 \AA^{-1}$. By contrast, the spectra of the eutrophic group (\#1 to \#3) show this phase maximum slightly shifted towards higher $\mathrm{k}$ values (Figure 3 , see arrows). This $\mathrm{k}$ shift changes continuously from sample \#1 to \#4. Thus roughly two groups of spectra can be identified: (i) The seven spectra of the oligotrophic section are almost invariant, which indicates a constant speciation with depth. (ii) The three spectra of the eutrophic section change continuously with depth.

The samples of the oligotrophic group were alternatively recovered from varved and homogeneous sections, with samples \#4 and \#8 coming from homogeneous zones and samples \#5, \#6, \#7, \#9 and \#10 originating from darker varved sections (Figure 1). The corresponding EXAFS spectra showed no variation with depth. Thus the EXAFS records showed no sensitivity to the varves in the sediment below $40 \mathrm{~cm}$. Chemical analyses indicated a relative increase of $\mathrm{Fe}$ bound AVS minerals in varved sections (Figure 1, Table I). However, the corresponding Fe fraction contributed only between $3.1 \%$ and $11.2 \%$ to the total Fe. This fraction was clearly 


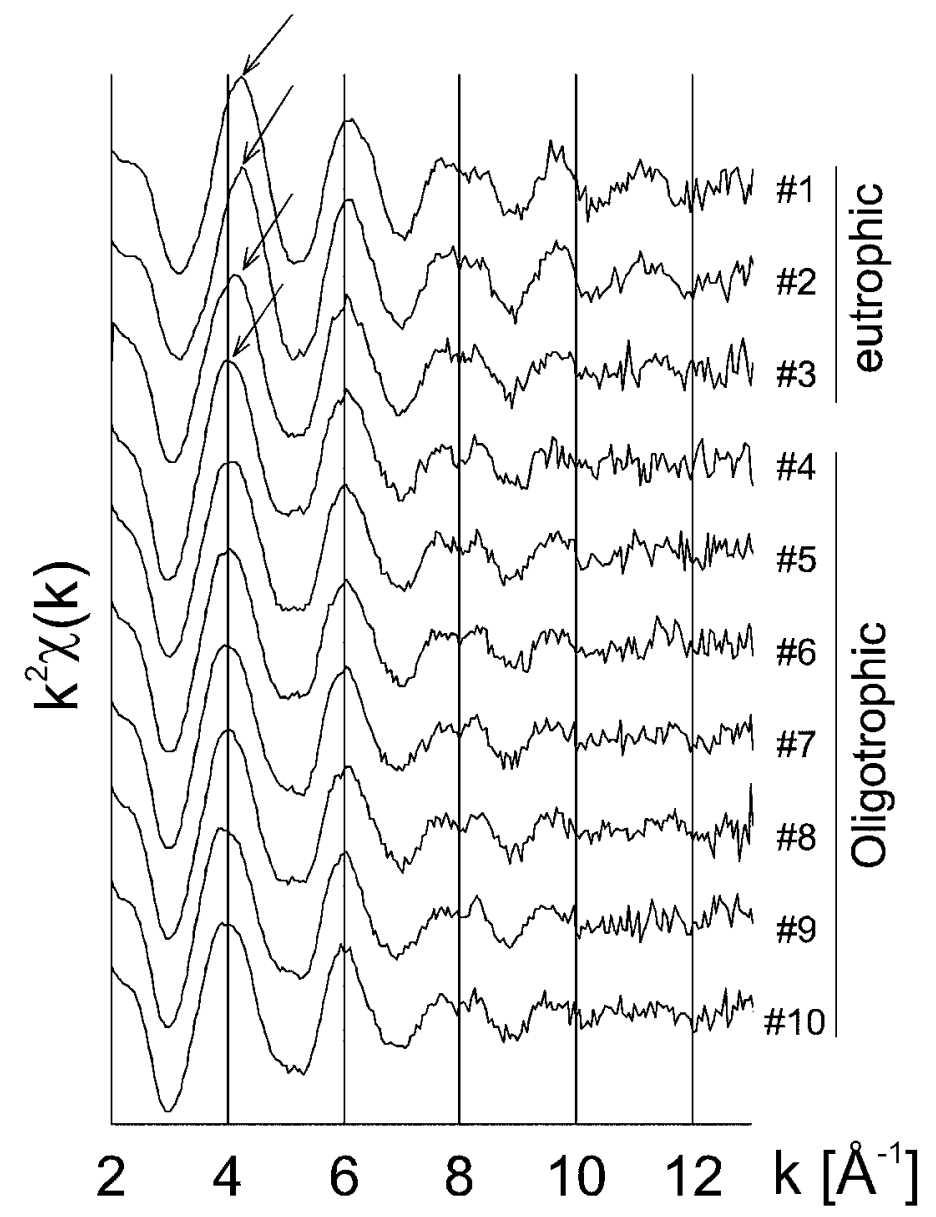

Figure 3. $\mathrm{k}^{2}$-weighted EXAFS spectra of sediment samples. Samples \#1 to \#3 were collected in the eutrophic section, and \#4 to \#10 in the oligotrophic section.

too low to be discriminated by EXAFS. The signal in the oligotrophic section is therefore certainly dominated by other non-sulfide Fe species.

The differences between oligotrophic and eutrophic samples can be qualitatively observed by comparing their radial distribution functions, RDF, obtained by Fourier transforming the $\mathrm{Fe}_{\mathrm{K}}$ EXAFS spectra (Figure 4). The RDF provides information on the Fe-oxygen or Fe-sulfur bond distances in the first coordination shell of Fe. The RDF of the samples \#1 and \#8 are plotted in Figure 4 together with some relevant reference compounds. The RDF position of the 1st peak relates to the mean Fe-1st shell distance. The samples \#1 and \#8 exhibit maxima at $1.9 \AA$ and $1.75 \AA$, respectively (Figure 4, dotted lines). This indicates a longer Fe-1st shell distance in sample \#1 compared to \#8. A first speciation hypothesis can be formulated when comparing these RDF to those of the reference minerals given in 


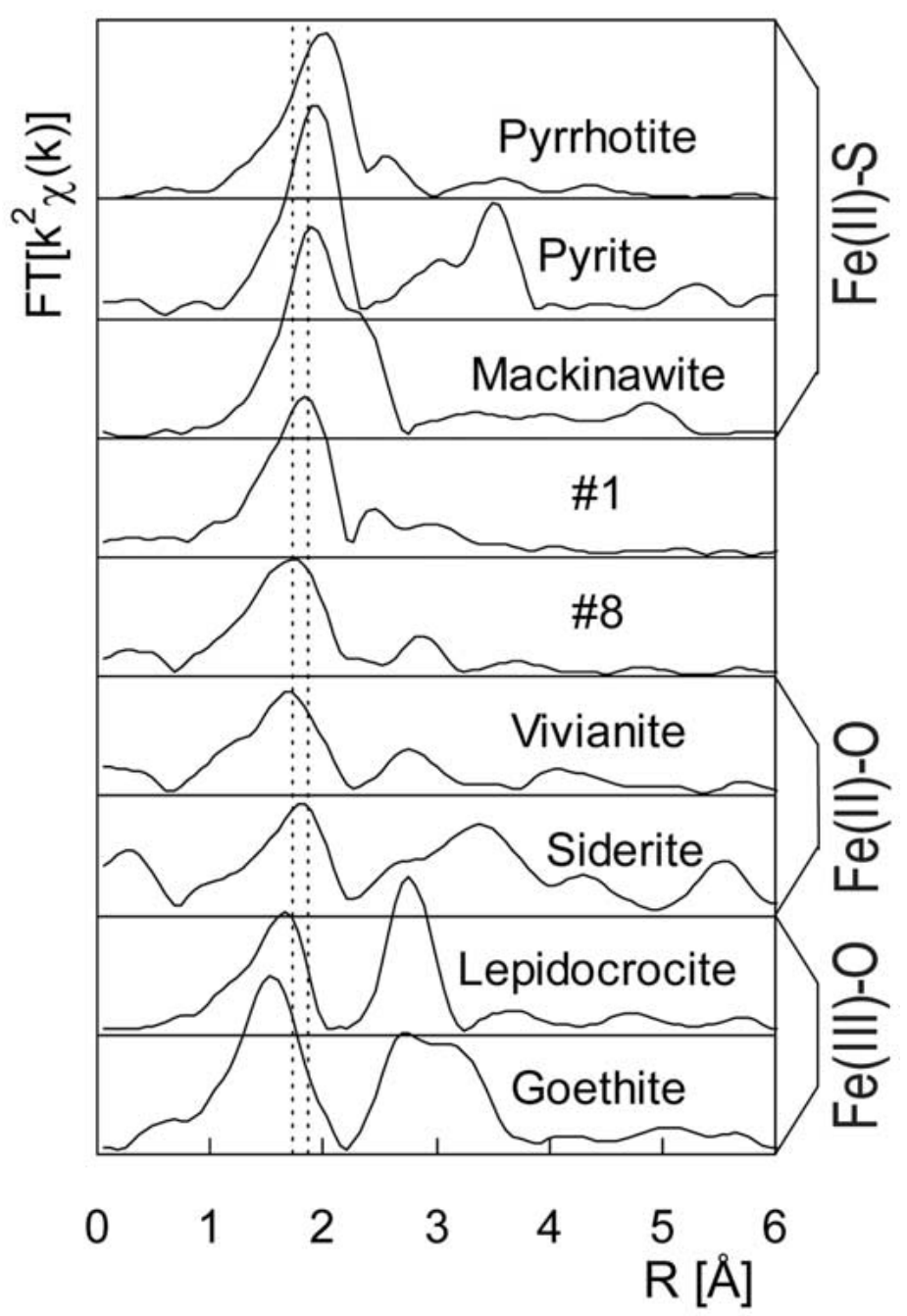

Figure 4. Radial distribution functions (RDFs) of the samples \#1 and \#8 compared with representative reference compounds.

Figure 4. The positions of the 1st shell maxima of both \#1 and \#8 compare best to those of vivianite and siderite. Both are Fe(II) minerals with an oxygen lattice. Thus major concentrations of $\mathrm{Fe}(\mathrm{II})-\mathrm{O}$ minerals are supposed to be present in both samples. In comparison, the 1st peak positions of Fe-sulfides (the Fe(II)-S group) appear at longer distances and the $\mathrm{Fe}(\mathrm{III})$-oxides distances (Fe(III)-O group) are shorter.

In more detail, the \#1 peak points to longer distances compared to the peak of \#8. It approaches positions of Fe(II)-S minerals. The spectrum \#1 from the eutrophic lake may thus incorporate simultaneously significant fractions of both $\mathrm{Fe}(\mathrm{II})-\mathrm{S}$ and $\mathrm{Fe}(\mathrm{II})-\mathrm{O}$ minerals. This first speciation hypothesis matches results 
of the chemical analysis (Figure 1, Table I). In the eutrophic range two major Fe fractions were detected with specific chemical extraction methods. The first fraction consisted of AVS minerals which contribute 22 (\#1), 40 (\#2) and $18 \%$ (\#3), respectively, to the total Fe concentration. This AVS fraction can be related to the Fe(II)-S group contributing to the EXAFS data in Figure 4. The second important fraction could be assigned to non sulfide Fe(II) minerals with contributions of 70 (\#1), 48 (\#2) and $74 \%$ (\#3), respectively, to the total Fe content. This fraction corresponds to the dominant contribution of the $\mathrm{Fe}(\mathrm{II})-\mathrm{O}$ group in the RDF of Figure 4. There are two important $\mathrm{Fe}(\mathrm{II})-\mathrm{O}$ mineral groups: phosphates and carbonates. In general, the total $\mathrm{P}$ concentration is too low to bind a significant fraction of the iron in the $\mathrm{Fe}(\mathrm{II})-\mathrm{O}$ group (Table I). The carbonates are therefore the most likely candidate for iron binding in these sediments.

\subsection{QUANTITATIVE SPECTRA ANALYSIS}

Statistical analyses of EXAFS data were performed with linear combinations of reference and sample $\mathrm{k}^{2} \chi(\mathrm{k})$ spectra and subsequent least square regression analysis. In a first round a systematic fit procedure was applied: all possible pair combinations of reference spectra (marcasite $\&$ siderite, marcasite $\&$ goethite etc.) were fitted to the sample spectra \#1 and \#8, respectively. The results are presented as a two dimensional map of the number of merit in Figure 5. The number of merit represents the sum of least squares between a EXAFS curve calculated as a linear combination of two reference spectra and the measured sample spectra. Crosses on a white background correspond to the best correspondence. The merit of the other squares decreases with increasing darkness.

Oligogrophic section. vivianite itself fits very well to \#8, all combinations including vivianite have correspondingly a good merit and most of the best solutions marked with a cross in Figure 5 include this reference mineral. The only competitive alternative combines siderite and ferrihydrite. Further linear combinations with good numbers of merit are found when combining two iron oxides, one oxide with siderite or some of the Fe-sulfide references (pyrrhotite, pyrite, troilite). This statistical approach identifies vivianite, siderite, some Fe oxides and Fe sulfides as potential major Fe bearing minerals in the oligotrophic section of the sediment. As already noticed Fe-phosphates are present as a minor fraction only. On the other hand, the best fitting mineral vivianite belongs to the $\mathrm{Fe}(\mathrm{II})-\mathrm{O}$ group. At this group level the fit result compares well to the speciation scheme expected from RDF findings in the oligotrophic section. Thus, whereas the method fails in correctly predicting the major mineral species the approach nevertheless results in a valuable proposition for the dominant mineral group.

Eutrophic section. All 'best' (cross) and 'good' (white square) combinations in sample \#1 involve Fe-sulfides. The presence of Fe(II)-S minerals in sample \#1 

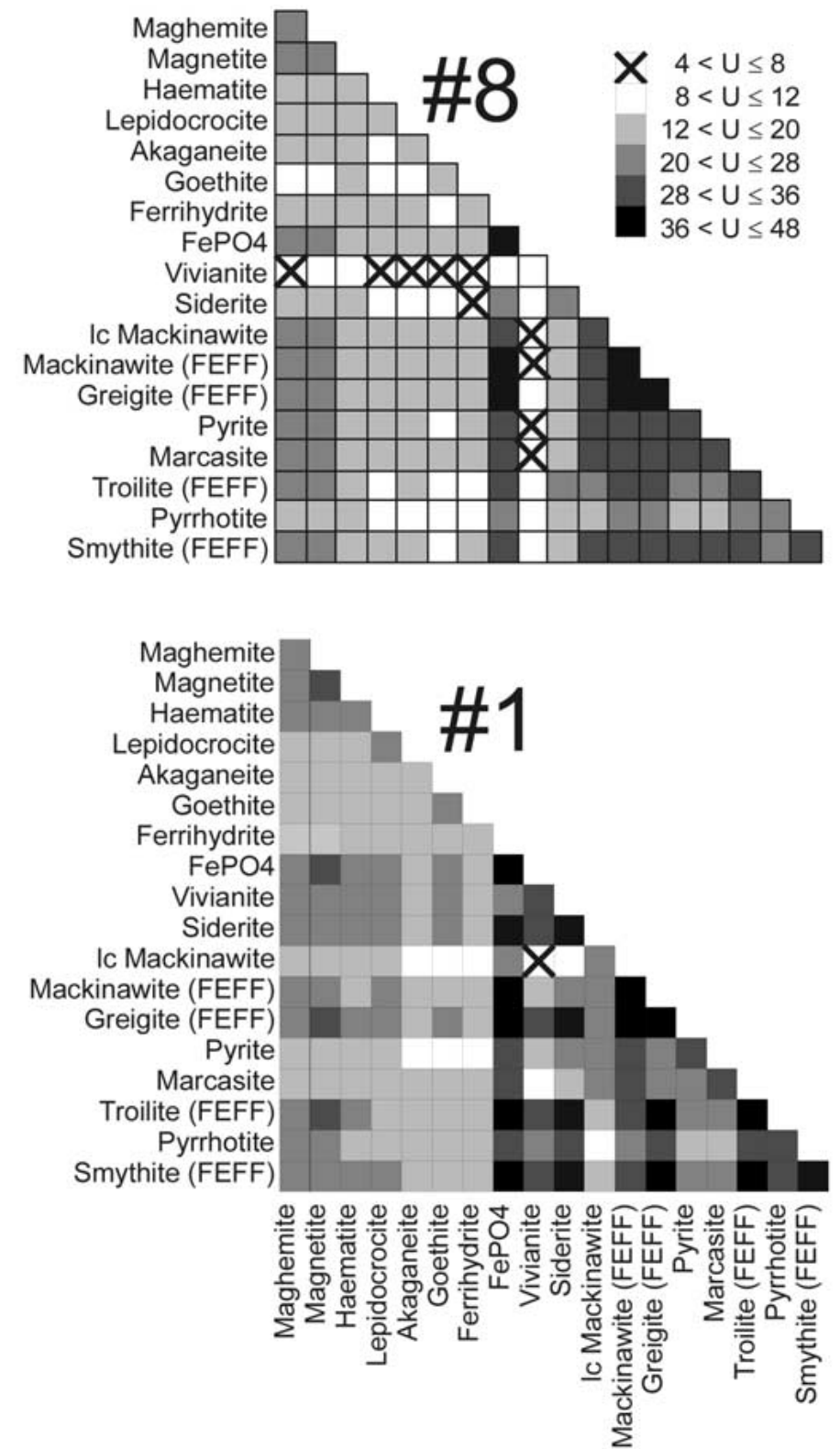

Figure 5. Map of least-squares sums obtained from the systematic fit procedure for samples $\# 8$ and \#1. The optimization was achieved by minimizing $\mathrm{U}$, defined as $\mathrm{U}=\Sigma\left(\mathrm{k}^{2} \chi \exp -\right.$ $\left.\mathrm{k}^{2} \chi_{\mathrm{th}}\right)^{2}$, where $\chi_{\exp }$ represents the observed EXAFS curve, and $\chi_{\mathrm{th}}$ stands for the calculated EXAFS curve. Greigite, troilite and smythite EXAFS spectra were generated with the FEFF7 code. FEFF intrinsic parameters were determined by adjusting theoretical and experimental spectra for available references. Structural data for pyrrhotite were taken from Nakano et al., (1979) and those for the idealized vacancy-free mackinawite structure from Uda et al, (1968). A defective mackinawite reference (lc) was synthesized according to (Berner, 1964) and confirmed by X-ray diffraction. 
is supported by chemical and comparative RDF findings. In particular, the best solution combines mackinawite and vivianite, thus an Fe-sulfide and a Fe(II)O compound. As for \#8, systematic fitting leads to valuable propositions of the dominant mineral groups but fails again in delivering reasonable combinations of mineral species. Vivianite can only represent a minor Fe bearing fraction according to the chemical analysis results. This species acts as a placeholder for an unknown $\mathrm{Fe}(\mathrm{II})-\mathrm{O}$ species with similar first shell properties as vivianite. On the other hand, the combined evidence of EXAFS and selective extraction suggests that mackinawite is effectively a major Fe-bearing mineral species.

Experimental $\mathrm{k}^{2} \chi(\mathrm{k})$ spectra were compared in more detail with a selection of references. Different weights (expressed in \%) were given to combinations of reference spectra. The three top fits in Figure 6 compare sample \#8 individually to each of the references vivianite, ferrihydrite and siderite. A common systematic deviation between \#8 and the three pure references is indicated at $5.3 \AA^{-1}$ by a vertical line in Figure 6: the $\mathrm{k}^{2} \chi(\mathrm{k})$ value of the \#8 spectrum is always significantly lower than those of the three reference compounds. It is thus mathematically not possible to solve this misfit by linearly combining the three reference spectra. These fits contrast with the particular fit given in Figure $6 \mathrm{~d}$, in which \#8 is fitted to \#1. This calculation yields the best one-component fit and confirms that the $\# 1$ and \#8 spectra are very close. No misfit is observed at $5.3 \AA^{-1}$ and the two spectra \#1 and \#8 exhibit both the same beating pattern at 7.7 to $8.3 \AA^{-1}$. This similarity suggests that a unique mineral species prevails in both samples \#1 and \#8 from the eutrophic and oligotrophic section, respectively. To assess this hypothesis fits with 2 and 4 components of sample \#8 were performed based on the original reference database excluding the \#1 spectrum in the fit procedure. Thus, Figure $6 \mathrm{e}$ is a 2-component fit based on siderite and ferrihydrite. Figure $6 \mathrm{f}$ represents a 4-component fit with the non-sulfide reference compounds vivianite, siderite, lepidocrocite and ferrihydrate. Both fits $6 e$ and $6 f$ are not satisfying, significant misfits prevail particularly at $5.3 \AA$. We therefore conclude that the reference database is not representative for the speciation in sample \#8. Reference spectra of major Fe species are missing, or sample and reference species may have a different local Fe order. The following section is dedicated to the solution of this specific problem.

\subsection{PROPOSED SPECIATION}

It was already mentioned that all ten samples are close in shape. This fact and in particular the common beating pattern between 7.7 and $8.3 \AA^{-1}$ (Figure 3) are considered as an indicator for the same major species existing in both sections of the core. We consider the \#8 spectrum as representative for the spectrum of the unknown species. This species can be attributed to the non sulfide Fe(II) fraction which largely dominates the Fe speciation in the oligotrophic section (Figure 1). The same fraction contributes significantly to the speciation in the eutrophic sec- 

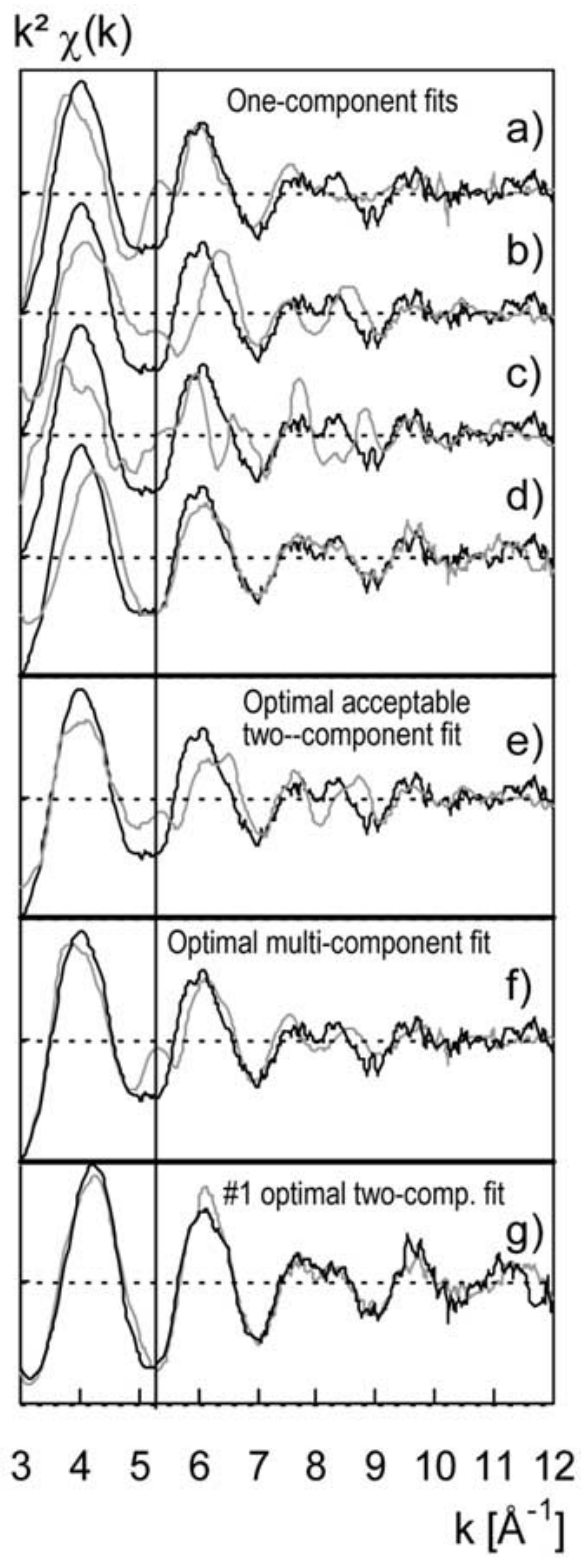

Figure 6. Experimental EXAFS spectra (black lines) compared to optimal model spectra obtained from reference compounds (grey lines). A weight of 2 is applied in the $\mathrm{k}$ range $7.0 \leq \mathrm{k} \leq$ 12.0. Optimization was achieved in minimizing $\mathrm{V}, \mathrm{V}=\Sigma\left(\mathrm{k}^{2} \chi_{\exp }-\mathrm{k}^{2} \chi_{\mathrm{th}}\right)^{2} / \Sigma\left(\mathrm{k}^{2} \chi_{\exp }\right)^{2}$. (a) to (f) represent models fitted to the \#8 spectrum among which (a) to (d) are one-component models: $86 \%$ vivianite (a) $(\mathrm{V}=0.073), 54 \%$ ferrihydrite (b) $(\mathrm{V}=0.10), 42 \%$ siderite (c) ( $\mathrm{V}=0.15), 71 \% \# 1(\mathrm{~d})(\mathrm{V}=0.056)$. (e) is the optimal acceptable two-component model: $47 \%$ ferrihydrite $+29 \%$ siderite $(\mathrm{V}=0.080)$, and (f) the optimal four-component model: $58 \%$ vivianite $+25 \%$ ferrihydrite $+58 \%$ lepidocrocite $+52 \%$ siderite $(\mathrm{V}=0.049)$. $(\mathrm{g})$ represent the optimal two-component model fitted to sample \#1: 78\% \#8 + 49\% lc mackinawite ( $\mathrm{V}=$ $0.035)$. 
tion where it adds to the AVS fraction. To assess this hypothesis a series of fits of the \#1 spectrum were performed with the \#8. The best two-component fit (Figure $6 \mathrm{~g}$ ) combines the \#8 spectrum and that of low crystalline (lc) mackinawite which contributes to the AVS fraction. All other two-component fits excluding the \#8 spectra have a significantly lower merit (data not shown).

The next question of interest concerns the mineralogical nature of the \#8 species. Fe replacing $\mathrm{Ca}$ in the calcite structure seems to be a valuable proposition to be tested: $\mathrm{CO}_{3}^{2-}$ ligands are abundant in the sediment, calcite and thus also a $\left(\mathrm{Ca}_{\mathrm{x}}\right.$, $\left.\mathrm{Fe}_{1-\mathrm{x}}\right) \mathrm{CO}_{3}$ solid solution may form (Filippi et al. 1998). In our previous study we found evidence for the formation of $\left(\mathrm{Ca}_{\mathrm{x}}, \mathrm{Mn}_{1-\mathrm{x}}\right) \mathrm{CO}_{3}$ (Friedl et al. 1997). An EXAFS spectrum of Fe containing calcite was not available. Therefore a theoretical $\left(\mathrm{Ca}_{\mathrm{x}}, \mathrm{Fe}_{1-\mathrm{x}}\right) \mathrm{CO}_{3}$ structure was calculated with the FEFF7 code (Rehr et al. 1991; Zabinsky et al., 1995).

\subsection{Calculation of The $\left(\mathrm{Ca}_{\mathrm{x}}, \mathrm{Fe}_{1-\mathrm{x}}\right) \mathrm{CO}_{3}$ STRUCtURe}

The structures of siderite $\mathrm{FeCO}_{3}$ and calcite $\mathrm{CaCO}_{3}$ are isomorphic. The central $\mathrm{Me}(\mathrm{II})$ ion is coordinated in both cases to 6 equidistant oxygen atoms (1st shell), 6 equidistant carbon atoms (2nd shell), 6 equidistant oxygen atoms ( $3 \mathrm{~d}$ shell) and 6 equidistant $\mathrm{Ca}$ (II) or $\mathrm{Fe}$ (II) ions (4th shell). The interatomic distances in these four shells are for siderite $2.14,3.00,3.26,3.73 \AA$, and for calcite 2.36, 3.21, 3.46, $4.05 \AA$, respectively. In a first step the siderite spectrum was simulated with the FEFF7 code (Rehr et al. 1991; Zabinsky et al., 1995) and compared to natural siderite to test the validity of the simulation. Calculated and measured siderite spectra do not compare adequately (Figure $7 \mathrm{a})$ : In the low $\mathrm{k}$ range $\left(\mathrm{k}<7 \AA^{-1}\right) \mathrm{a}$ significant phase shift is observed, increasing with decreasing $\mathrm{k}$ values. In addition, calculated and experimental beating patterns do not compare at $\mathrm{k}<5 \AA^{-1}$. Such strong differences are not acceptable, specifically when considering the sensitivity of linear combination fitting to phase shifts. Removing next-nearest second $\mathrm{C}$ and third $\mathrm{O}$ shells (Figure 7b) improves the match between calculation and experiment. Therefore, to deduce an optimized structure a stepwise approach was followed. In Figure 7c, the \#8 spectrum is compared to a calculation of a siderite $\mathrm{FeO}_{6}$ octahedron $\left(\mathrm{d}_{\mathrm{Fe}-\mathrm{O}}=2.144 \AA\right.$ ). The comparison shows that the two spectra do not compare in phase. A much better fit is obtained for $\mathrm{a} \mathrm{FeO}_{6}$ octahedron fixed at a shortened $\mathrm{d}_{\mathrm{Fe}-\mathrm{O}}=2.080 \AA$. In a next step, the 2 nd $\mathrm{O}$ and $3 \mathrm{~d} \mathrm{C}$ shells were placed at halfway between siderite and calcite Me-shell distances. Finally, the FeCa distance in the 4th shell was fixed at $3.94 \AA$. The generally good concordance between the experimental \#8 spectrum and the calculated Fe-calcite spectra given in Figure $7 \mathrm{~d}$ thus supports the postulated $\left(\mathrm{Ca}_{\mathrm{x}}, \mathrm{Fe}_{1-\mathrm{x}}\right) \mathrm{CO}_{3}$ species. The postulated structural parameters will have to be verified in further studies. Based on both the EXAFS analysis and the chemical data we propose that the $\left(\mathrm{Ca}_{\mathrm{x}}, \mathrm{Fe}_{1-\mathrm{x}}\right) \mathrm{CO}_{3}$ solidsolution represents a dominant $\mathrm{Fe}(\mathrm{II})$ bearing species in the oligotrophic sediment of Baldeggersee. Iron(III) phases are also present, probably in the form of lepido- 


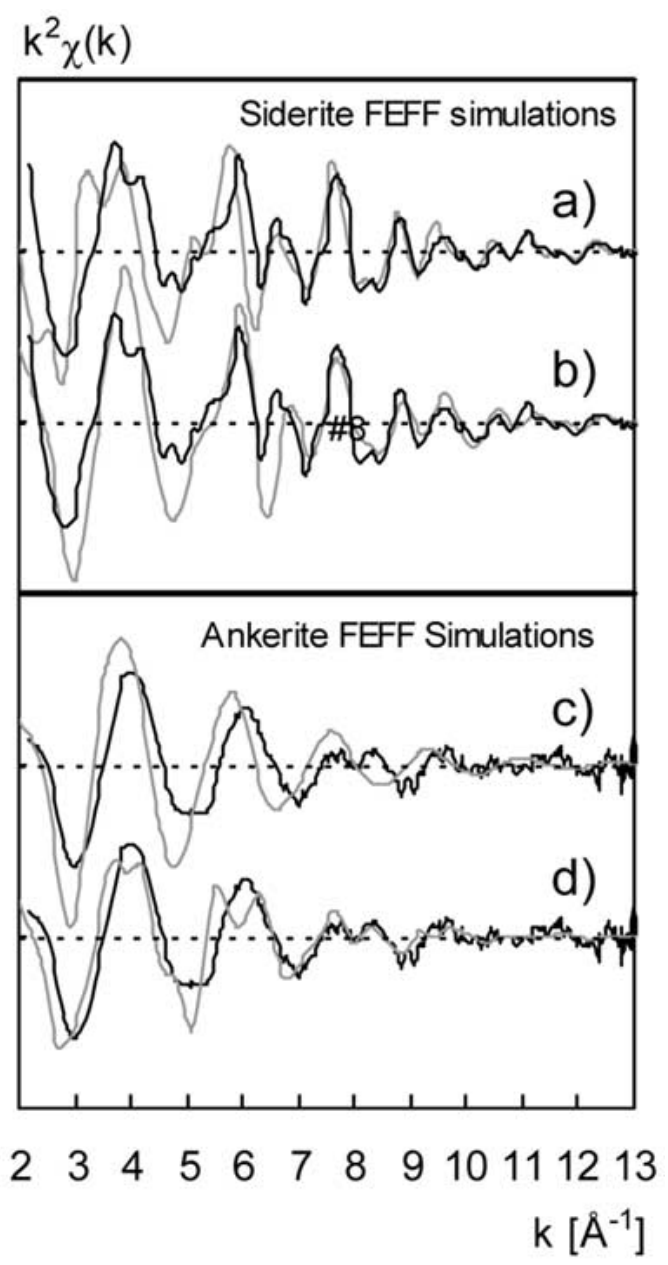

Figure 7. Experimental (black lines) compared to theoretical (grey lines) $\mathrm{Fe}_{\mathrm{K}}$ EXAFS spectra calculated $a b$ initio with the FEFF7 code. (a) calculated and experimental siderite spectra. (b) same as (a), but the 2nd and $3 \mathrm{rd} \mathrm{C}$ and $\mathrm{O}$ shells are removed in the simulation. (c) the \#8 spectrum compared to a calculated siderite $\mathrm{FeO}_{6}$ octahedron with a $\mathrm{Fe}-\mathrm{O}$ distance of $2.144 \AA$ ). (d) the \#8 spectrum compared to the $\left(\mathrm{Ca}_{\mathrm{x}}, \mathrm{Fe}_{1-\mathrm{x}}\right) \mathrm{CO}_{3}$ simulation with the 1st and 4th shells fixed at $\mathrm{d}(\mathrm{Fe}-\mathrm{O})=2.08 \AA$ and $\mathrm{d}(\mathrm{Fe}-\mathrm{Ca})=3.94 \AA$ ) .

crocite and/or ferrihydrate. In the eutrophic section, mackinawite appears as further major species.

\section{Conclusions}

To our best knowledge the present study is the first one which applies EXAFS spectroscopic methods to analyze the speciation of iron in lake sediments. The work thus allows some first conclusions about the potential of bulk EXAFS analysis 
and linear combination techniques to decipher the Fe speciation in such complex matrices. In our case the method proved successful in deciphering the major Fe species when combined to chemical selective extraction methods. In principle, EXAFS analysis allowes detecting major individual mineral species, whereas specific chemical extraction methods only indicate groups of minerals such as the AVS and CRS fraction. The two methods are thus complementary. In complex mixtures bulk EXAFS may allow to discriminate solely the dominant species. In particular the linear combination fit approach requires the a priori knowledge of the reference compounds and the associated EXAFS spectra. Thus major species not included in the database may be disregarded. In the given case mackinawite and the $\left(\mathrm{Ca}_{\mathrm{x}}\right.$, $\left.\mathrm{Fe}_{1-\mathrm{x}}\right) \mathrm{CO}_{3}$ solid solution compound could be inferred only by combining EXAFS and chemical analysis results. Also, diagenetic minerals may be more or less substituted and their EXAFS spectra may differ significantly from well-crystallized reference compounds. The validation of EXAFS fits with results from selective extraction is therefore essential.

\section{Acknowledgments}

The study was performed within the frame of a bilateral French-Swiss PICS project (No. 310) co-financed by the French CNRS, the French ministry of foreign affairs and the Swiss national science foundation SNF (NF-20-47136.96). The authors gratefully acknowledge the LURE synchrotron facility in Orsay for beamtime.

\section{References}

Berner R. A. (1964) Iron sulfides formed from aqueous solutions at low temperatures and atmospheric pressure. J. Geol. 72, 293-306.

Bott M. (2002) Iron sulfides in Baldeggersee during the last 8000 years: Formation processes, chemical speciation and mineralogical constraints from EXAFS spectroscopy. Ph. D. thesis, ETH, Zürich.

Burdige D. J. (1993) The biogeochemistry of manganese and iron reduction in marine sediments. Earth Science Reviews 35, 249-284.

Cornell R. M. and Schwertmann U. (1996) The Iron Oxides. Structure, Properties, Reactions, Occurrence and Uses. VCH Verlagsgesellschaft, Weinheim.

Davison W. (1993) Iron and manganese in lakes. Earth-Science Reviews 34, 119-163.

Drodt M., Trautwein A. X., König I., Suess E. and Bender Koch C. (1997) Mössbauer spectroscopic studies on the iron forms of deep-sea sediments. Phys. Chem. Minerals 24, 281-293.

Filippi M. L., Lambert P., Hunziker J. C. and Kubler B. (1998) Monitoring of detrial input and resuspension effects on sediment trap material using mineralogy and stable isotopes (delta O-18 and delta C-13): The case of Lake Neuchatel (Switzerland). Palaeogeogr. Palaeoclim. Palaeoecol. 140, 33-50.

Friedl G., Wehrli B. and Manceau A. (1997) The role of solids in the cycling of manganese in eutrophic lakes - new insights from EXAFS spectroscopy. Geochim. Cosmochim. Acta 61, 275290.

Hansel C. M., Fendorf S., Sutton S. and Neville M. (2001) Characterization of Fe plaque and associated metals on the roots of mine-waste impacted aquatic plants. Environ. Sci. Technol. 35, $3863-3868$. 
Koningsberger D. C. and Prins R. (1988) X-ray Absorption. John Wiley \& Sons, New York.

Kuno A., Matsuo M. and Numako C. (1999) In situ chemical speciation of iron in estuarine sediments using XANES spectroscopy with partial least-squares regression. J. Synchrotron Radiation $\mathbf{6}$, $667-669$

Lotter A. F., Sturm M., Teranes J. L. and Wehrli B. (1997) Varve formation since 1885 and highresolution varve analyses in hypertrophic Baldeggersee (Switzerland). Aquat. Sci. 59, 304-325.

Manceau A., Lanson B., Schlegel M. L., Harge J. C., Musso M., Eybert-Berard L., Hazemann J. L., Chateigner D. and Lamble G. (2000) Quantitative Zn speciation in smelter-contaminated soils by EXAFS spectroscopy. Am J. Sci. 300, 289-343.

Mettler S., Abdemoula M., Hoehn E., Schoenenberger R., Weidler P. and von Gunten U. (2001) Characterization of iron and manganese precipitates from an in situ ground water treatment plant. Ground Water 39, 921-930.

Morse J. W., Millero J. M., Cornwell J. C. and Rickard D. (1987) The chemistry of the Hydrogen Sulfide and Iron Sulfide systems in natural waters. Earth Science Reviews 24, 1-42.

Nakano A., Tokonami M. and Morimoto N. (1979) Refinement of 3C pyrrhotite, $\mathrm{Fe}_{7} \mathrm{~S}_{8}$. Acta Cryst. B35, $722-724$.

Nirel P. M. V. and Morel F. M. M. (1990) Pitfalls of sequential extractions. Water Res. 24, 1055-1056.

Rehr J. J., Mustre de Leon J., Zabinsky S. I. and Albers R. C. (1991) Theoretical X-ray absorption fine structure standards. J. Am. Chem. Soc. 113, 5135-5145.

Sarret G., Manceau A., Spadini L., Roux J.-C., Hazemann J.-L., Soldo Y., Eybert-B,rard L. and Menthonnex J. J. (1998) Structural determination of $\mathrm{Zn}$ and $\mathrm{Pb}$ binding sites in Penicillium chrysogenum cell wall by EXAFS spectroscopy. Envir. Sci. Technol. 32, 1648-1655.

Schaller T., Moor H. C. and Wehrli B. (1997) Sedimentary profiles of Fe, Mn, V, Cr, As and Mo recording signals of changing deep-water oxygen conditions in Baldeggersee. Aquatic Sciences 59, 345-361.

Taillefert M., Lienemann, C.-P., Gaillard J.-F. and Perret D. (2000) Speciation, reactivity, and cycling of $\mathrm{Fe}$ and $\mathrm{Pb}$ in a meromictic lake. Geochim. Cosmochim. Acta. 64, 169-183.

Uda M. (1968) The structure of tetragonal FeS. Zeitschr. Anorg. Allg. Chem. 361, 94-98.

Zabinsky S. I., Rehr J. J., Ankudinov A., Albers R. C. and Eller M. J. (1995) Multiple scattering calculations of X-ray absorption spectra. Phys. Rev. B 52, 2995-3009. 